\title{
Re-inventing community psychiatry in the United States
}

\author{
JOHN A. TALBOTT
}

Community psychiatry began in the United States because of the confluence of several factors (Talbott, 1982). These included: (1) the establishment of alternatives to psychiatric hospitals, the first of which was established in the United States in 1855, (2) the development of a wide range of community program elements in the early 20th century, (3) the articulation of the concepts of community psychiatry, which also developed in the 20th century, (4) the articulation of models and plans for community mental health, which date to $1950,(5)$ the deinstitutionalization of psychiatric hospital patients beginning in 1955 , and finally (6) the federal legislation that authorized the planning, construction and staffing of community mental health centers across the country in 1965.

However, despite this 150 year history of extra-institutional care and 30 years after federal legislation (John F. Kennedy's Community Mental Health Center Act) - radically different forms of care for the mentally ill are only now becoming a reality and for very different reasons than one imagined 30 or even ten years ago. But I'm jumping ahead of myself.

\section{FACTORS THAT BROUGHT ABOUT COMMUNITY PSYCHIATRY IN AMERICA}

From the discovery and establishment of this relatively new nation in 1492 , care of the mentally ill was absent, disorganized or took place in institutions designed for others, e.g., workhouses, poorhouses and almshouses (Talbott, 1983). With the building of psychiatric hospitals, which began with the «Pub-

\footnotetext{
Indirizzo per la corrispondenza: Professor J.A. Talbott, Department of Psychiatry, University of Maryland School of Medicine, Baltimore, MD 21201 (USA).

Fax +1 410-3283.693.
}

lick» Hospital in Williamsburg, Virginia in 1773, the country experienced an unprecedented growth in the number of such facilities and most care of the severely mentally ill in the United States was undertaken in them.

(1) Alternatives to hospitals were initiated in the US in 1855 with the Farm at St. Anne's. Since then, alternatives of a variety of types were introduced (figure 1).

(2) The program elements that comprise community psychiatry include alternatives but also other elements such as brief therapy, interdisciplinary teams and prevention (table I).

(3) Likewise, the concepts of community psychiatry are also broad, encompassing such issues as comprehensive treatment, continuity of care and public health (table II).

(4) Models for community centers were articulated beginning with the World Health Committee in 1954 and the subsequent plans designed by New York State and the US Federal government simply expanded the necessary ingredients (table III).

(5) Deinstitutionalization of our large psychiatric hospitals began in 1955. By today their censuses have reduced to almost one-sixth what they were at their peak (figure 2).

(6) The community mental health center (JFK) legislation provided the finalization of this process, putting into law the required ingredients. The specifics are shown above in table III, column 3.

\section{THE ECLIPSE OF COMMUNITY PSYCHIATRY}

Unfortunately, for the movement, the achievements of community psychiatry and community mental health centers were soon overshadowed by the disastrous consequences of unplanned and untested deinstitutionalization, for which we were to- 
Table I. - Program elements in community psychiatry.

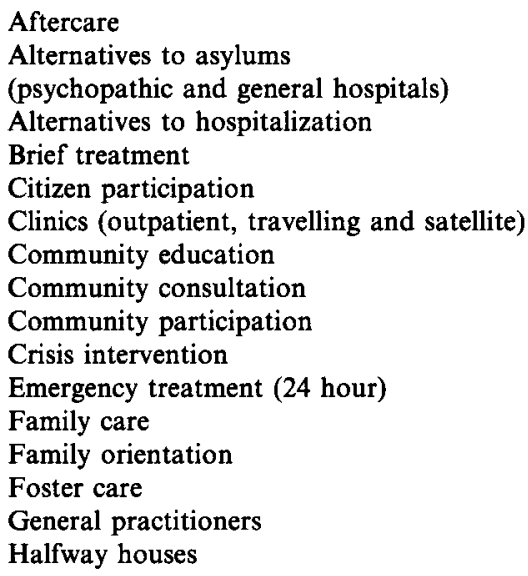

Table II. - Concepts of community psychiatry.

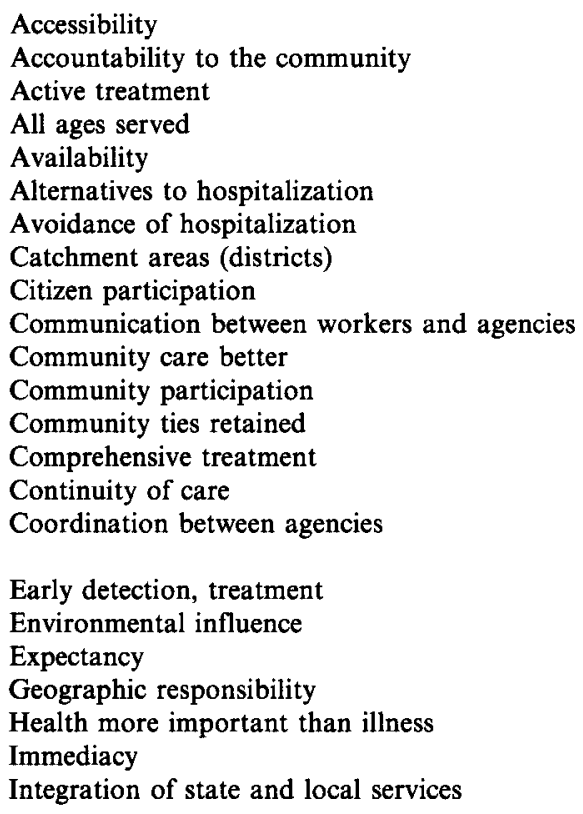

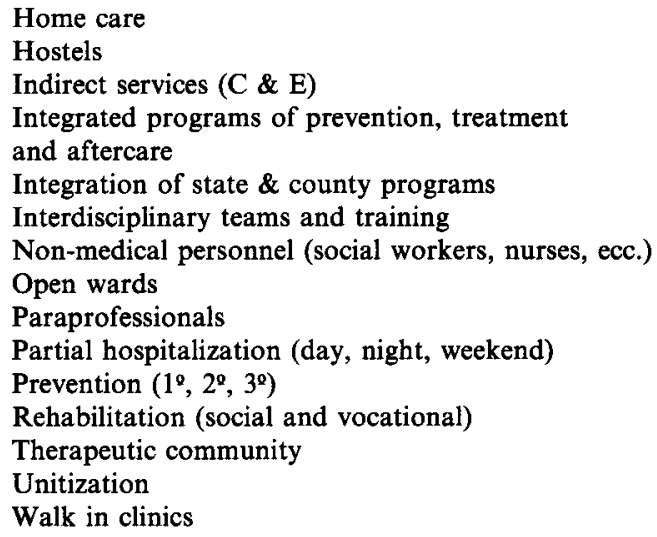

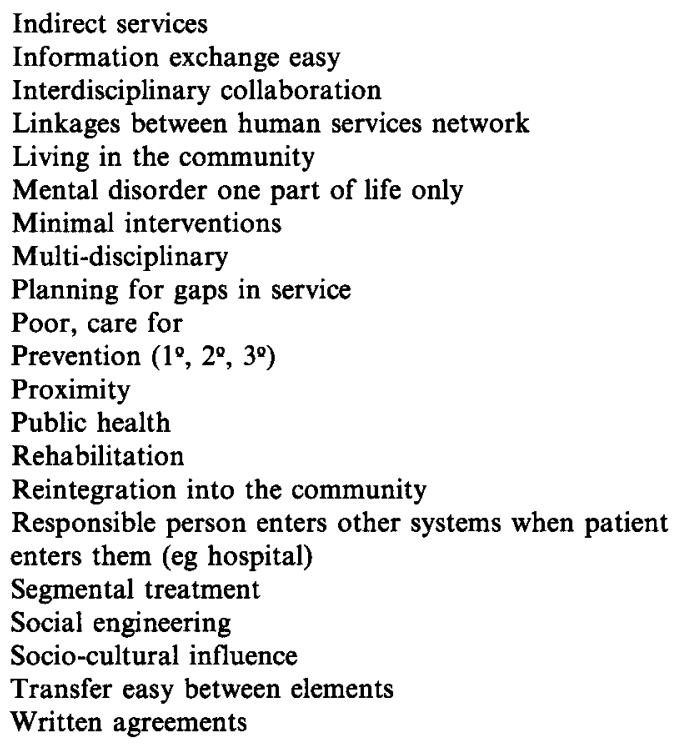

tally unprepared. By the mid-1970's, its victims were all too visible on our nation's streets - the homeless mentally ill, those suffering from mental illness and substance abuse, and the thousands of mentally ill persons «transinstitutionalized» to nursing homes, prisons and a variety of usually abysmal «community residences" (Talbott 1978a,b).

As has been ably articulated in the Committee on Psychiatry and Community of the Group for the Advancement of Psychiatry Publication (1983) commu- nity psychiatry was in fact much more than just buildings. However, in reifying the movement into concrete "centers» rather than community programs, many of the concepts that underlay the movement (in table II) such as flexibility, continuity of care and comprehensive treatment and rehabilitation were lost.

Also, many CMHC's became over-democratic, with interdisciplinary staff voting on patient treatment plans; over-reaching, concerned more with rat 
Table III. - Components of Community Mental Health Centers.

\begin{tabular}{|c|c|c|c|}
\hline \multirow[b]{2}{*}{ WHO Committee (1954) } & \multirow[b]{2}{*}{ New York State (1954) } & \multicolumn{2}{|c|}{ Regulations } \\
\hline & & CMHC (1965) & CMHC Amendment (1975) \\
\hline & Inpatient & Inpatient & Inpatient \\
\hline Outpatient & Outpatient & Outpatient & Outpatient \\
\hline \multirow[t]{2}{*}{ Partial hospital } & & Partial hospital & Partial hospital \\
\hline & & Emergency $(24-\mathrm{hr})$ & Emergency (24-hr) \\
\hline \multirow[t]{2}{*}{ Community education } & Consultation and education & $\begin{array}{l}\text { Consultation and education } \\
\text { Diagnostic }\end{array}$ & Consultation and education \\
\hline & & Precare and aftercare & $\begin{array}{l}\text { Screening patients for courts } \\
\text { and agencies prior to state } \\
\text { hospital } \\
\text { Follow-up care }\end{array}$ \\
\hline \multirow{7}{*}{$\begin{array}{l}\text { Rehabilitation } \\
\text { Research }\end{array}$} & Rehabilitation & Rehabilitation & \\
\hline & & Research and evaluation & \\
\hline & & & Transitional housing \\
\hline & & & Services for elderly \\
\hline & & & Services for children \\
\hline & & & Services for alcoholics \\
\hline & & & Services for drug problems \\
\hline
\end{tabular}

control than psychosis; and over-committed, taking on community organization, primary prevention and community consultation in areas, not then proven to be effective or efficient.

However, many programs, to community psychiatry's immense credit, incorporated the best community psychiatry had to offer, e.g., prompt treatment, alternatives to hospitals and continuity of care and dropped what seemed less relevant, e.g., community control, primary prevention and social engineering. Thus, in many academic medical centers, many persons who would a few years before have called themselves community psychiatrists, now said they were practicing modern psychiatry or state-of-the-art science with the severely ill.

\section{THE RE-INVENTION OF COMMUNITY PSYCHIATRY}

As mentioned in my introduction, however, and ironically, it is not simply the ideologic, programmatic and/or governmental emphasis on community psychiatry that has caused immense ferment in the United States prompting changes in the health care system that profoundly effect care, treatment and rehabilitation of the severely mentally ill - it is the economic forces.
Traditionally, providers (e.g., physicians, hospitals and clinics) were paid for each visit rendered or each bed occupied " after the fact. In the 1980's this began to change to a price being established for each diagnostic grouping "before the fact. In addition, starting in the Nixon era, entities called health maintenance organizations (HMO's) were authorized, whose purpose it was to concentrate on keeping people healthy rather than on only treating their illnesses. While, in the early days, these HMO's were more concerned with cost-cutting than «health maintenance», and to achieve that goal disallowed treatment of persons with severe mental illnesses, things are changing. HMO's were joined by other forms of group practices as well as by firms that «managed» care by conducting pre-treatment authorization, periodic reviews and "capping» some expenditures. Now over half of insured Americans have their care «managed", and with the addition of the poor and elderly, enrolled in federal Medicare and federal/state Medicaid programs, this number will grow.

Capitating populations, that is, providing so many dollars per person per month or year, enables providers of care to decide where patients are best treated. With a capitated population, any entity cannot just provide inpatient or outpatient or rehabilitative care. One must have a full-spectrum of services, with ease of access between them, assertive outreach, keen follow-up, and utilization by both effectiveness 


\section{Vocational Rehabilitation}

Halfway House

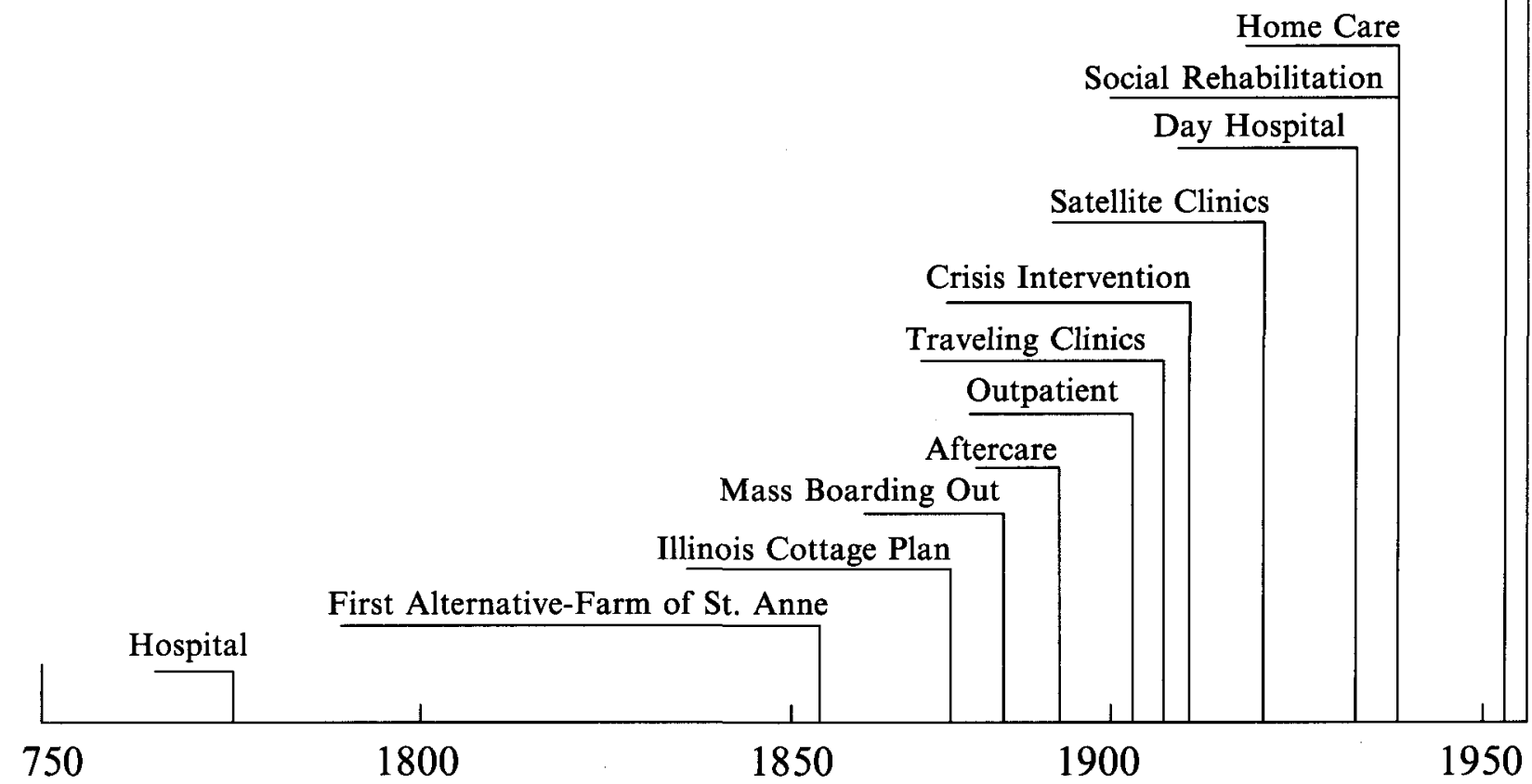

Figure 1. - Alternatives to State hospitals. Starting in 1855 a number of alternative programs to State hospitals were established in the United States.

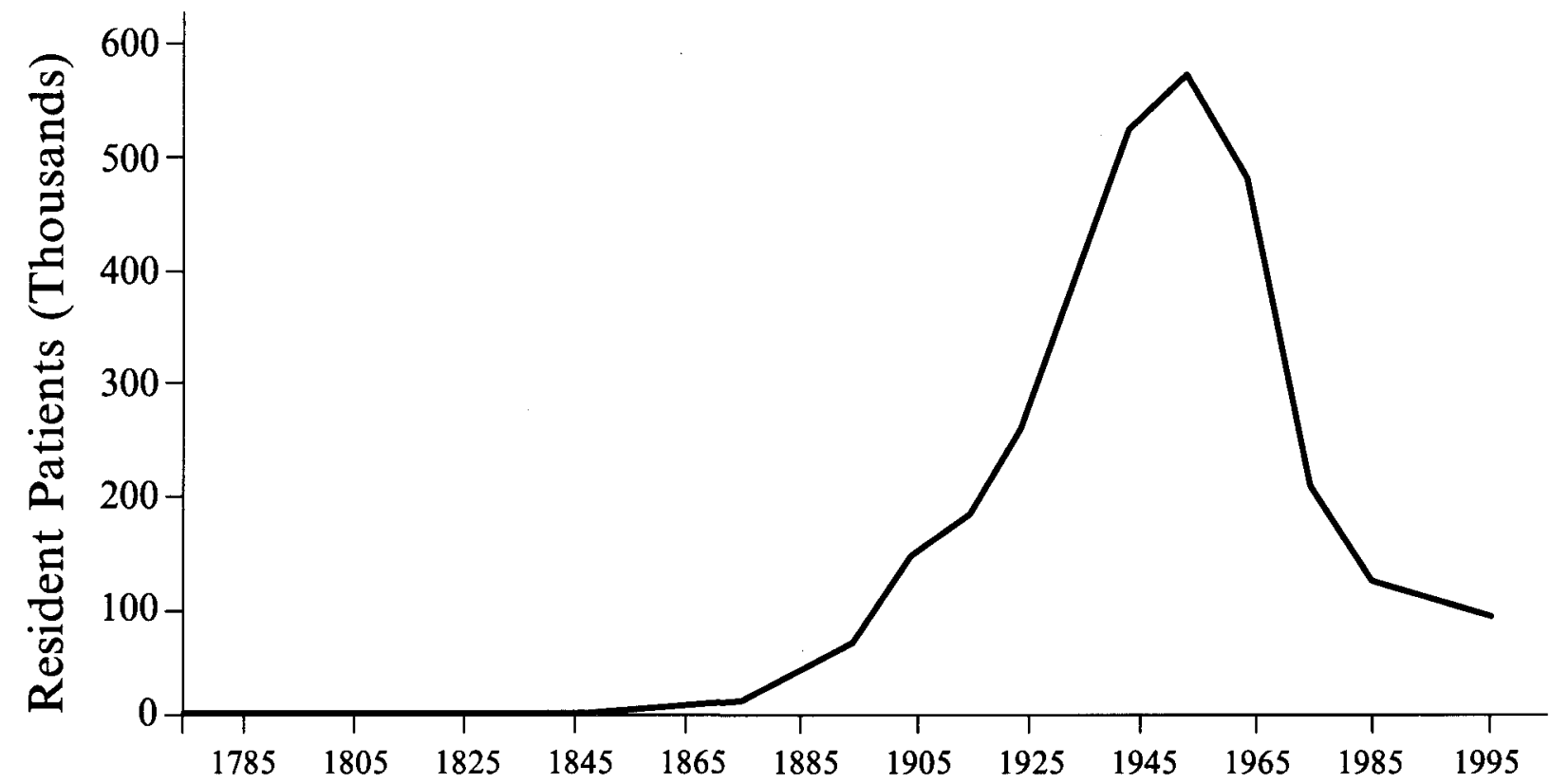

Figure 2. - State hospital population. After a peak in 1955 , deinstituzionalization resulted in an $80 \%$ decrease over the next three decades. 
and efficiency and well as an assessment of patient outcomes and accountability. Thus, through the free-market forces that exist, there is finally an opportunity to return to the principles, ideals, concepts and program elements of community psychiatry articulated $30-40$ years ago.

Again, ironically, it is also the very leaders in community psychiatry and public sector care of the severely and chronically mentally ill who are leading these new care systems, whether they are HMO's, Managed Care entities, or comprehensive academic medical center service systems bidding for contracts with industry, labor, other health entities or the government when it comes to the poor, disabled and elderly.

Federal national health care reform in the United States has been left in the dust of this tremendous new movement, which took place locally, on a state-level or by population groups. But the future for those with severe and chronic mental illnesses no longer looks so bleak as it did at the height of the impact of deinstitutionalization. Indeed with capitation and the ability to control where monies should go, the severely and chronically mentally ill may well be the ultimate victors in the re-invention of community psychiatry.

\section{REFERENCES}

Committee on Psychiatry and Community of the Group for the Advancement of Psychiatry, (1983). Community Psychiatry: a Reappraisal. Mental Health Materials Center, American Psychiatric Press: Washington, DC.

Talbott J.A. (1978a). The Death of the Asylum: a Critical Study of State Hospital Management, Services, and Care. Grune and Stratton: New York.

Talbott J.A. (1978b). The Chronic Mental Patient: Problems, Solutions, and Recommendations for a Public Policy. American Psychiatric Association: Washington, DC.

Talbott J.A. (1982). Twentieth-century developments in American psychiatry. Psychiatric Quarterly 54(4), 207-219.

Talbott J.A. (1983). Trends in the development of psychiatric services. In Psychiatric Administration: a Comprehensive Text for the Clinician-Executive (ed. J.A. Talbott and S.R. Kaplan), pp. 3-19. Grune and Stratton: New York. 